\title{
Uma visão institucional para a dívida pública no Brasil
}

\author{
An institutional vision for public debt in Brazil
}

MARCEL GUEDES LEITE ${ }^{1}$

PAULO ROBERTO ARVATE ${ }^{2}$

RESUMO: O objetivo deste artigo é encontrar um pedido de desculpas teórico à alocação pública da dívida sobre a riqueza financeira dos agentes, dados os padrões sucessivos impostos pelo setor público às exigências da dívida pública.

PALAVRAS-CHAVE: dívida pública, instituições, riqueza financeira.

ABSTRACT: The purpose of this article is found a theoretical apology to the debt public allocation on agents' finance wealth given the successive defaults enforced by public sector to debt public demanding.

KEYWORDS: public debt, institutions, financial wealth.

JEL Classification: H6.

\section{INTRODUÇÃO}

Quando terminávamos um trabalho empírico sobre que variáveis determinariam a alocação da dívida interna pública na riqueza financeira dos agentes privados, verificamos que: ${ }^{3}$

1. dos vinte e sete anos disponíveis da série representativa da taxa real de jurosutilizada por nós (SELIC - 1974 a 2000), doze anos apresentavam taxas negativas. ${ }^{4,5}$

\footnotetext{
${ }^{1}$ Professor da Pontifícia Universidade Católica - PUC, São Paulo/SP, Brasil. E-mail: magle@uol.com.br; Orcid:0000.0001.9305.9703.

${ }^{2}$ Professor da Pontifícia Universidade Católica - PUC, São Paulo/SP, Brasil. E-mail: Parvate@fgv.br; Orcid: 0000-0003-4466-6165.

${ }^{3}$ Arvate \& Leite (2000).

${ }^{4} \mathrm{O}$ apêndice ao final do texto apresenta a evolução da taxa real de juros e a da composição da dívida pública interna na riqueza financeira (M4).

${ }^{5}$ Grande parte dos anos em que a taxa real de juros foi positiva está concentrada nos anos noventa. Na
} 
2. não existia qualquer causalidade significativa entre a série representativa dataxa real de juros e a série representativa da composição da dívida pública interna na riqueza financeira dos agentes privados (Títulos públicos fora da carteira do Banco Central sobre M4) ou vice-versa. ${ }^{6}$

Como se tratavam de séries temporais, um exame prévio sobre a estacionariedade das séries foi realizado para não realizarmos uma regressão espúria. Fugindo ao padrão Box-Jenkins para identificação da estacionariedade, observamos nos testes de raíz unitária - Augmented Dickey-Fuller (ADF) e PhillipsPerron (PP) — que:

- as séries de títulos públicos fora da carteira do Banco Central, denominada TITULOS, e a série da taxa real de juros, denominada SELIC, caracterizaram-se como não estacionárias, porém integradas de ordem 1 - I (1);

- apesar do padrão de estacionariedade das séries, não há qualquer relação linear entre as mesmas ao nível de $5 \%$ de significância; ${ }^{7}$

- complementarmente a isto, pelo teste de Granger, não se encontrou qualquer causalidade significativa entre as séries.

De tudo o que foi descrito, intrigava-nos mais a não estacionariedade da série TITULOS (crescente) frente a um período relativamente extenso de taxas reais negativas. ${ }^{8}$ O que explicaria isto? Falando de maneira mais específica: o que levaria os agentes privados a alocar de forma crescente a dívida pública interna na sua riqueza financeira com taxas reais negativas??

$\mathrm{Na}$ nossa visão, este comportamento dos agentes privados seria explicado pela criação e desenvolvimento de regras: regras que levaram a dívida pública interna a assumir as funções da moeda e a realizar uma espécie de hedge contra a inflação. Na literatura não havia nenhum artigo que tratasse a questão desta forma. Apenas Fischer (1985) introduziu títulos indexados na riqueza dos agentes privados para verificar se os mesmos, por reduzirem o impacto da inflação, serviriam como um hedge aos títulos nominais que não possuíssem indexação. Pelos resultados apresentados, somente os ativos reais, equities, cumpririam a função de hedge para os títulos nominais; não os títulos indexados. ${ }^{10}$

visão de alguns autores, e entre eles inclui-se Pinotti\&Pastore (1999), este resultado não aconteceu por questões de mercado vinculadas à dívida pública em si. As taxas nominal e real foram elevadas num primeiro momento para conter a demanda agregada e, num segundo momento, para atrair capitais externos em face da política de financiamento do déficit em Transações Correntes.

${ }^{6}$ Houve dificuldade de manter o conceito dívida interna pública fora do Banco Central nos anos setenta porque o Banco Central não publicou a série com a mesma metodologia. Para atender o mesmo período da SELIC assumimos algumas hipóteses para construir a série da dívida. Veja ANDIMA (1993).

${ }^{7} \mathrm{O}$ teste de Johansen rejeitou qualquer cointegração entre as mesmas.

${ }^{8}$ Vide apêndice 1.

${ }^{9}$ É quase impossível determinar o rendimento líquido da dívida pública interna devido a diversidade de títulos que a compõe e mudam seu grau de importância na composição da dívida pública como um todo ao longo do tempo. Afora isto, a estrutura tributária também foi alterada de tempos em tempos.

${ }^{10}$ Se isto fosse verdade, este hedge determinaria um prêmio aos títulos públicos, reduzindo seu custo para o setor público. Não foi o que se observou. 
Tendo os resultados acima e um estudo mais profundo das regras que interferiram na decisão dos agentes no mercado da dívida pública interna, conseguimos definir o objetivo deste trabalho: construir um modelo que justificasse a decisão ótima dos agentes de carregar dívida pública interna em sua riqueza apesar de seus sucessivos rendimentos negativos.

Duas seções serão necessárias para desenvolvermos este objetivo. Na primeira seção será apresentado o conjunto de regras que afetam a decisão dos agentes no mercado da dívida pública interna de duas formas. Primeiro, produzindo incerteza sobre o rendimento da dívida pública interna devido a possibilidade de mudanças nas regras. ${ }^{11,12}$ Segundo, tornando a dívida pública interna substituta perfeita da moeda.

$\mathrm{Na}$ segunda seção tomaremos a dívida pública interna moldada pelas regras existentes e, com um modelo alocativo de riqueza à Tobin de dois ativos, moeda e dívida pública, mostraremos como serão as condições de ótimo para os agentes privados. Teremos três resultados: uma solução de alocação apenas com moeda, outra apenas com dívida pública ou com os dois ativos presentes na riqueza (o resultado mais usual). Estas soluções é que possibilitaram a idéia chave do artigo: a dívida pública, apesar dos seus sucessivos rendimentos negativos, cumpriu o papel de hedge para o poder de compra da moeda reduzindo as suas perdas frente à inflação. Passemos ao desenvolvimento.

\section{REGRAS, REGRAS E MAIS REGRAS: A CONSTRUÇÃO INSTITUCIONAL DE UM ATIVO ${ }^{13}$}

Como se dá a atuação das instituições no mercado de empréstimos? Instituições são regras como descrito por North (1990). Especificamente, nosso interesse é a descrição e a articulação das regras que moldaram os títulos da dívida pública interna no mercado de empréstimos. Evidenciaremos nesta seção do trabalho que durante um período relativamente extenso da economia brasileira, o entendimento do que seja dívida pública interna, moldada por este conjunto de regras, é diferente do entendimento de um ativo que não possua esta perspectiva. ${ }^{14}$ Algumas posições que parecem não tão bem elucidadas sobre o comportamento dos agentes com relação a alocação de sua riqueza ficam claras na presença destas regras. Neste sentido, voltamos a afirmar, nossa hipótese é a de que a avaliação da dívida pública interna neste mercado depende das regras existentes. É o que veremos à seguir:

\footnotetext{
${ }^{11}$ Como veremos na descrição, grande parte dos rendimentos negativos se deve a mudança de regra na correção monetária.

12 Fischer (1985) incluiu o componente estocástico nos preços. Mantivemos a inflação vigente e incorporamos a incerteza apenas na mudança da regra em função de nossos objetivos.

${ }^{13}$ Procuraremos dar exemplos de regras que destacam o argumento desenvolvido. Arvate (1999) apresenta quase todas as regras.

${ }^{14}$ Meados dos anos setenta até o início dos anos noventa.
} 


\section{2.a. Regra de aplicação da correção monetária.}

A partir de 1964, no bojo do Plano de Ação Econômica do Governo (PAEG), o mercado de empréstimos beneficiou-se de uma regra que, à partir daquele momento, corrigiria nominalmente os débitos do setor público junto aos agentes privados e os débitos dos agentes privados para com o setor público.

Por que esta regra foi importante para a dívida pública interna? Porque os papéis públicos, todas as vezes que se defrontavam com um processo inflacionário, impunham violentas perdas aos seus detentores em termos reais. ${ }^{15}$

A adoção desta regra permitiria que os títulos públicos passassem a contar com uma maior proteção frente a inflação. Se isto fosse alcançado, o resultado direto desta medida seria que estes papéis, que não eram tão bem avaliados no mercado em termos de risco, melhorariam a sua avaliação e permitiriam que o setor público recuperasse uma importante fonte de financiamento. ${ }^{16}$

Observando o que ocorreu após a implantação da regra, o esperado se concretizou: a dívida pública interna passou a ser um papel de primeira linha em termos de classificação de risco e o setor público pode novamente contar com esta fonte de financiamento.

Tudo transcorreu normalmente até 1974 , ano em que começaram a ocorrer as primeiras mudanças na regra de correção monetária. ${ }^{17}$ Inicialmente com objetivos que não visavam impor perdas diretamente a quem carregava os títulos da dívida pública interna mas com este objetivo na seqüência, o setor público começou a instrumentalizar a regra de correção monetária com mudanças constantes na sua fórmula de correção.

Diante da mudança na funcionalidade da regra, começou-se a desenvolver no mercado a percepção de que a regra de correção monetária era tão somente uma regra de aplicação da correção monetária e nada além disso. Uma regra em que as perdas eram previsíveis mas com a sua forma de ocorrência variando ao longo do tempo. ${ }^{18}$ Sendo assim, o mercado passou a trabalhar em função de uma nova pers-

\footnotetext{
${ }^{15}$ No que foca especificamente a dívida interna, o principal elemento das mudanças ocorridas nesta época foi a institucionalização da correção monetária, com a emissão das Obrigações Reajustáveis do Tesouro Nacional, as ORTNs. A criação destes novos papéis acabou com os rendimentos negativos até então registrados nos título públicos, devido ao cenário de inflação ascendente. ANDIMA (1993).

${ }^{16}$ Resende (1982) deixa claro que...O desenho do arcabouço básico de um sistema financeiro moderno, associado à correção monetária nos contratos e títulos financeiros de médio e longo prazos, permitiu a captação de poupança privada voluntária e sua canalização para o financiamento tanto do Tesouro quanto do investimento privado.

${ }^{17}$ É importante neste momento destacar a reestruturação do mercado para títulos públicos no início dos anos setenta. Veja em Cysne (1995) o depoimento de Carlos Brandão sobre o assunto.

${ }^{18}$ Um exemplo do seu efeito indireto foi a política adotada pelo setor público a partir de 1974 que visava não levar em conta no cálculo da correção monetária as altas de preços provocadas por mudanças no clima ou na conjuntura internacional (acidentalidade). Um outro exemplo do efeito direto foi o
} 
pectiva de ocorrência, não na dúvida da ocorrência que já era dada como certa. ${ }^{19}$ Parece-nos que houve um retrocesso frente ao que se desejava na descrição inicial da regra visto que as perdas voltaram. Surpreendente a tudo isso é que, apesar das perdas, o setor público não perdeu esta fonte de financiamento, nem a dívida pública interna perdeu a sua condição de papel de primeira linha no mercado. ${ }^{20}$ As perdas aconteceram mas em nada o status da dívida pública foi derrubado no mercado. $\mathrm{O}$ que aconteceu? Como isso foi possível? Regras. Regras agora produzidas no âmbito do Sistema Financeiro que se articulavam com a regra de aplicação da correção monetária e com o momento inflacionário vivido à partir da primeira década de setenta.

\section{2.b. Regras criadas no âmbito do Sistema Financeiro que transformaram a dívidapública interna num ativo de elevada liquidez.}

Paralelamente à criação da regra de correção monetária, começou-se a desenvolver um conjunto de regras no âmbito do Sistema Financeiro. Regras estas que são fundamentais para se entender a entrada do Sistema Financeiro e dos agentes privados no jogo montado pelo setor público. ${ }^{21}$ Dois grupos de regras poderiam ser separados metodologicamente: num primeiro grupo, regras que foram criadas para o Sistema Financeiro pela própria Autoridade Monetária e, num segundo grupo, regras criadas pelo Sistema Financeiro para os agentes privados.

\section{2.b.1. Regras criadas para o Sistema Financeiro.}

Uma série de normas foi editada pela Autoridade Monetária — na medida que a regra de aplicação da correção monetária se tornava mais usual este quadro fica mais evidente - no sentido de aumentar o carregamento de títulos da dívida pública por parte das instituições financeiras. Alguns exemplos são mencionados no histórico a seguir:

- na própria edição do PAEG, foi permitido que $15 \%$ (percentual aumentado progressivamente até $55 \%$ em 1970) dos depósitos compulsórios dos bancos comerciais junto ao Banco Central fossem utilizados em ORTNs, bem

\footnotetext{
default aplicado no Plano Collor sob os detentores da dívida pública interna. Outros exemplos podem ser vistos em Arvate (1999).

${ }^{19}$ Ocorre, entretanto, que a forma equivocada com que o governo encarou o endividamento público desde então, quebrando regras contratuais através de expurgos na correção monetária, acabou por afetar a credibilidade da sociedade em sua capacidade de pagamento. Tal descrédito gerou, inclusive, o chamado "prêmio de risco" para os compradores de título públicos - terminologia habitual na análise da dívida pública ao longo da década de 80 e o início dos anos 90, ANDIMA (1993). Parece-nos equivocado o termo "prêmio de risco" visto que quem gerou o custo de transação foi a estrutura de regras vigentes.

${ }^{20}$ Veja o comportamento da série TITULOS no apêndice.

${ }^{21}$ Os agentes privados são os tomadores finais desses papéis.
} 
como pudessem fazer parte das reservas técnicas das seguradoras e dos fundos de investimento. 22,23

Após a crise de liquidez no sistema em 1975, a Resolução número 366 em 09/ 04/76 permitiu a recompra automática de títulos federais por parte da Autoridade Monetária. ${ }^{24}$ Esta regra facilitou a alavancagem em papéis públicos por parte das instituições financeiras dado que o risco na retenção desses papéis deixou de existir: qualquer problema de liquidez era garantido pela Autoridade Monetária. ${ }^{25}$

Já a Resolução número 860 , também de $12 / 10 / 84$, elevou de $10 \%$ para $22 \%$ a taxa do compulsório sobre depósitos a prazo, sendo que a diferença deveria ser recolhida em novas ORTNs monetárias. ${ }^{26}$

Até 1990 o patrimônio dos fundos de pensão era utilizado como instrumento de política monetária. Por mais de uma década o governo estipulou limites mínimos para aplicação em títulos públicos federais, passando por letras hipotecárias da Caixa Econômica Federal, Debêntures da Siderbrás e tantos outros títulos de retorno duvidoso, até que em 1990 o setor questionou judicialmente a compulsoriedade imposta pelo governo na compra de certificados de privatização. Os fundos de pensão saíram vencedores. ${ }^{27}$

A instrumentalização das instituições financeiras é tão sintomática com relação ao carregamento de títulos públicos que Llussá (1997), com dados apenas para os anos noventa, constatou a não existência de uma diferença significativa no longo prazo entre a taxa da SELIC, que representaria o risco público, e a taxa do CETIP, que representaria o risco privado. $\mathrm{O}$ excessivo montante de títulos públicos no Ativo destas instituições fez com que o risco privado fosse considerado o risco público. De qualquer forma, se as perdas existiram durante um longo período, a pergunta que se faz na seqüência é o porquê das instituições financeiras participarem deste jogo. Qual seria a sua vantagem?

No caso das instituições financeiras, elas como intermediárias entre o setor público e os agentes privados na negociação destes papéis, maximizam seu lucro quanto maior for o spread. Mesmo que exista uma taxa negativa para elas, havendo uma taxa negativa ainda maior para o tomador final destes títulos, a possibilidade do ganho existirá e justificará a sua participação neste jogo. Foi exatamente

\footnotetext{
${ }^{22}$ Fonte ANDIMA (1993).

${ }^{23}$ ORTNs são as Obrigações Reajustáveis do Tesouro Nacional. Um dos diversos nomes dados a títulos públicos no Brasil. No caso brasileiro, como em qualquer lugar do mundo, os títulos são emitidos pelo Tesouro ou Banco Central. Eles diferem quanto aos indexadores de correção e prazo. Veja ANDIMA (1993).

${ }^{24}$ Fonte ANDIMA (1993).

${ }^{25}$ Esta regra deixou de existir à partir de 1986.

${ }^{26}$ Fonte ANDIMA (1993).

${ }^{27}$ Costa e Silva (1996). Apesar desta menção, a Resolução do Conselho Monetário Nacional que flexibilizou os limites da quantidade de títulos públicos na carteira dos fundos de pensão foi a número 2206, de 25/10/95.
} 
isto que se observou: a resposta passiva das instituições financeiras ao conjunto de normas adotadas pela Autoridade Monetária foi possível porque mesmo com taxas negativas para o sistema, a possibilidade do lucro sempre existiu. ${ }^{28}$ Os agentes privados retinham estes papéis a uma taxa negativa ainda maior que aquela das instituições financeiras.

Acompanhando o argumento, o porquê das instituições financeiras participarem deste jogo fica elucidado. O que se tem a fazer então é entender o porquê da participação dos agentes privados neste mesmo jogo. Passemos a isto.

\section{2.b.2. Regras criadas pelo Sistema Financeiro.}

A partir de 1974, quando a inflação começou a ser um problema macroeconômico relevante e persistente, até o início dos anos noventa quando a taxa real de juros ficou fortemente positiva por problemas no Balanço de Pagamentos, a regra de aplicação da correção monetária, é bom frisar novamente dado a articulação entre as regras existentes, fez com que os detentores finais deste ativo, como vimos, os agentes privados, tivessem perdas contínuas. ${ }^{29,30}$

Vendo a questão pelo lado das regras, a medida que a situação de perdas ficava evidente aos agentes privados, o Sistema Financeiro passou a incorporar uma tendência de levar a zero o custo de transação e o deságio na saída das aplicações do mercado onde eram negociados os títulos da dívida pública. ${ }^{31}$

Como consequiência direta desta tendência foi possível aos agentes privados ficarem menos expostos aos efeitos da inflação aplicando e desaplicando diariamente em títulos públicos segundo as suas necessidades de caixa na realização de suas transações. ${ }^{32}$

\footnotetext{
${ }^{28}$ Existe alguma confusão entre os ganhos com intermediação de operações e os ganhos com imposto inflacionário que as instituições financeiras tiveram. No nosso caso, estamos falando de ganhos com a intermediação de operações. É claro que existindo depósitos à vista nos bancos, houve uma parcela do imposto inflacionário que ficou retido pelos mesmos. Isto explica a elevada lucratividade dos bancos no período inflacionário e a sua dificuldade de ajuste no momento da queda da inflação. Muitas instituições foram socorridas pelo Banco Central no programa conhecido por PROER. Veja para isto Barros \& Almeida Júnior (1997). O que dissemos foi que o spread, diferença entre as taxas passiva e ativa, sempre existiu e segundo PUGA (1999), não há resposta significativa entre seus movimentos e os movimentos da inflação.

${ }^{29}$ Deve-se mencionar o destaque que fizemos em relação aos anos noventa.

${ }^{30}$ Não se pode afirmar com certeza, mas se a taxa real de juros não fosse alterada no início dos anos noventa por necessidades externas, este mecanismo poderia ser aplicado até a edição do Plano Real.

${ }^{31} \mathrm{Na}$ verdade o zero de deságio era possível devido à curta maturidade dos papéis da dívida pública interna. Acompanhando a maturidade da dívida pública interna na publicação da ANDIMA (1993), fica claro que ele nunca foi um título de longo prazo quando comparado a títulos de países como Estados Unidos e Inglaterra.

32 Néri \&Camargo em Baumann (2000) mencionam que: "Durante o período de alta inflação no Brasil, os títulos do governo eram indexados à inflação, e extremamente líquidos. Os agentes que mantinham contas bancárias conseguiam proteger a sua riqueza financeira da inflação utilizando os títulos do governo como reserva de valor. O grupo de mais baixa renda não dispunha de contas bancárias, e assim não conseguiu
} 
A convivência com regras que determinavam a ausência do custo de transação na desaplicação ou deságio na saída deste papel fez com que os agentes privados revissem o seu ótimo de alocação de riqueza e usassem não apenas a moeda como um ativo de liquidez. Durante este período de perdas, a moeda e a "dívida pública interna", modificada por todo este corpo de regras articuladas, existiu uma substitubilidade muito maior do que a encontrada normalmente entre estes ativos. A dívida pública interna passou a assumir a função reserva de valor da moeda dado que a mesma protegia mais a parcela de liquidez dos agentes privados. E o resultado deste procedimento pode ser acompanhado na série TITULOS vista no apêndice.

Se os títulos da dívida pública foram condicionados pelas regras existentes e se transformaram neste ativo que compete com a moeda em termos de liquidez, porque a dívida pública interna neste estágio não assumiu integralmente o papel da moeda? É o que destacaremos na segunda parte deste artigo.

\section{UM HEDGE CONTRA AS PERDAS}

Bastaria a restrição de Clower, em que moeda compra bens e bens não compram bens, para afirmarmos não ser possível conviver sem moeda na realização de transações. ${ }^{33}$ Embora a moeda tenha reduzido no momento de inflação sua participação relativa na riqueza dos agentes, a dívida aumentou está participação com taxas reais negativas. Adotando a articulação de regras da seção anterior, apresentaremos a decisão ótima dos agentes num modelo que justifique este comportamento. ${ }^{34}$ Passemos às hipóteses de construção.

\subsection{Hipóteses de construção.}

1.1. a moeda e a "dívida pública interna" são os dois ativos que disputam aparcela de riqueza dos agentes privados destinada a liquidez; ${ }^{35,36}$

proteger os seus saldos em espécie da inflação. Havia outras formas de proteger que eram acessíveis ao grupo de baixa renda: previsão de consumo e compra de material de construção, por exemplo”.

${ }^{33}$ Veja a sua aplicação no modelo de gerações justapostas em Blanchard \& Fischer (1989), cap. 5.

${ }^{34}$ Trabalharemos apenas com os agentes avessos ao risco. A situação de ficar exclusivamente com um dos ativos pode existir se os agentes privados tiverem um comportamento de jogadores (amantes do risco) ou tiverem um comportamento de indiferença em relação ao risco. No primeiro caso, basta apenas que a utilidade esperada da renda deste jogador seja sempre maior para um ativo do que para outro para que a decisão seja tudo ou nada e, no segundo caso, basta apenas comparar a remuneração de ambos os ativos para escolher entre um deles. O caso mais interessante e mais recorrente, é dos agentes avessos ao risco.

${ }^{35}$ Focalizamos nossa atenção sobre os ativos que disputam a parcela da riqueza destinada a liquidez em função do nosso objetivo. Nada impede a inclusão de outros ativos e a construção de um modelo mais geral como aquele realizado por Fischer (1985).

${ }^{36}$ A dívida pública interna ganhou esta condição diante do quadro institucional descrito anteriormente. 
1.2. não há custo de transação ou deságio na mudança de alocação entre moeda e dívida pública interna; ${ }^{37}$

1.3. os agentes têm comportamento avesso em relação ao risco; ${ }^{38}$

1.4. existe uma regra de indexação para correção nominal da dívida pública interna baseada na inflação vigente; ${ }^{39}$

1.5. a quebra de regra é caracterizada com diferentes mudanças no que foi es-tabelecido para a indexação de forma a prejudicar a correção nominal da dívida pública nas mãos dos agentes privados. Os agentes privados sabem deste procedimento segundo o qual a regra é quebrar a regra. Como descrevemos, existe uma regra de aplicação da correção monetária que pode ou não ser cumprida. Não vamos tratar, como Fischer (1985), de títulos com correção nominal estocástica nos preços. Existirá incerteza em relação à mudança de regra, não em relação à mudança nos preços. ${ }^{40}$

A regra da aplicação da correção monetária varia desde a manutenção da regra vigente de indexação até uma quebra regra que seja superior ao não pagamento da inflação vigente. Em última instância, a quebra de regra pode reduzir em termos nominais o estoque de dívida que os agentes privados possuem. $\mathrm{O}$ limite para isto é tudo que os agentes possuem em termos de dívida pública interna. ${ }^{41}$

Se a regra de aplicação da correção monetária sobre a dívida pública interna vai de menos infinito até um (quando se cumpre a regra), considerando $\alpha$ o fator determinante da quebra de regra, se B é a parcela destinada a dívida pública interna, no limite teremos: ${ }^{42}$

$$
\operatorname{Lim}_{\alpha \rightarrow-\infty} B=0
$$

1.6. vale o princípio da não-saciedade: a utilidade esperada da renda é uma função crescente da renda.

\footnotetext{
${ }^{37}$ Este condição também advém do sistema institucional vigente.

${ }^{38}$ A função de utilidade esperada da renda frente ao risco é estritamente côncava.

${ }^{39} \mathrm{O}$ nosso foco será a quebra da regra estabelecida, não se uma regra de indexação baseada a inflação futura ou passada é mais eficiente ou menos eficiente. Nosso foco é sobre a incerteza da regra.

${ }^{40}$ Nada impediria tratar conjuntamente preços — com um componente estocástico — e a mudança de regras. Optamos por não usar o componente estocásticio nos preços porque, no caso brasileiro, não foi ele quem permitiu a utilização da moeda como hedge mas a construção institucional. No caso de Fischer (1985), os ativos reais, equities, fizeram o papel de hedge dos ativos nominais em relação à mudança estocástica dos preços.

${ }^{41}$ Pelo histórico institucional da dívida pública interna brasileira, as situações ocorridas, dentro do período escolhido por este trabalho, foram abrangidas por esta hipótese. Vide as situações descritas em Arvate (1999).

$42-\infty \leq \alpha \leq 1$
} 
1.7. a questão tributária não será considerada na definição do retorno real dos ativos. $^{43}$

\subsection{O modelo.}

1. a riqueza destinada à liquidez será dada por:

$L=M+B$

onde $L$ é a riqueza dos agentes privados destinada à ativos de liquidez,

$M$ é a parcela destinada a moeda,

$B$ é a parcela destinada a dívida pública interna.

2. a rentabilidade da moeda será dada por:

$r=-\pi$

onde $r$ é a taxa real de retorno da moeda, $\pi$ é a taxa de inflação. ${ }^{44}$

3. a rentabilidade da "dívida pública interna" será dada por:

$i(1+\alpha \pi)=r+\pi$

onde $i$ é o rendimento nominal da dívida interna, $\alpha$ é o componente de incerteza em relação ao cumprimento da regra de indexação, ${ }^{45}$

$\pi$ é a taxa de inflação, $r$ é a taxa real de retorno da "dívida pública interna".

4. a rentabilidade conjunta dos dois ativos de liquidez será dada por:

$R=\{i(1+\alpha \pi)-\pi\} B+(-\pi)(L-B)$

onde $R$ é a rentabilidade conjunta dos dois ativos de liquidez.

Eliminando um termo da equação (4):

$R=\{i(1+\alpha \pi)\} B-\pi L$

$\mathrm{O}$ rendimento que os agentes privados esperam de seus ativos de liquidez dependem da fixação nominal do rendimento da "dívida pública interna", da aplicação da regra de correção nominal deste débito e do imposto inflacionário sobre a moeda que os mesmos reterão.

\footnotetext{
${ }^{43}$ Nosso objetivo é entender o papel da "dívida pública interna" como um todo na riqueza financeira dos agentes privados. No caso brasileiro, a dívida pública interna na riqueza dos agentes privados possui diferentes títulos que mudaram ao longo do tempo com prazos diferentes. Se já é difícil construir uma série de dívida fora do Banco Central, torna-se praticamente impossível trabalhar com retornos líquidos para o setor público como um todo. Do ponto de vista de modelo poder-se-ia trabalhar com tributos. Acreditamos que nada ganharíamos em nosso objetivo neste trabalho. Veja ANDIMA (1993).

${ }^{44}$ A moeda não apresenta rendimento nominal.

${ }^{45}$ Definido nas hipóteses do modelo.
} 
5. a utilidade esperada do rendimento dos ativos de liquidez será:

$$
F(B)=E V\{[i(1+\alpha \pi)] B-L \pi\}
$$

a primeira e segunda derivadas da utilidade esperada serão:

$$
\begin{aligned}
& F^{\prime}(B)=E\{i(1+\alpha \pi)\} V^{\prime}\{[i(1+\alpha \pi)] B-L \pi\} \\
& F^{\prime \prime}(B)=E\{i(1+\alpha \pi)\}^{2} V^{\prime \prime}\{[i(1+\alpha \pi)] B-L \pi\}
\end{aligned}
$$

Em virtude das possíveis mudanças de regra, três soluções possíveis são colocadas como ótimas aos agentes privados em termos de alocação:

A) quando a quebra de regra é muito forte $(\alpha>1 / \pi)$ : a quebra de regra determinou uma redução nominal na "dívida pública interna".

Se isto ocorre, $\mathrm{E}\{\mathrm{i}(1+\alpha \pi)\}<0$.

Pela equação (7), a primeira derivada é negativa. Este é um caso em que a solução ótima será não reter nada em termos de "dívida pública interna" como ativo de liquidez. No mínimo a moeda perde a inflação vigente enquanto que a "dívida pública interna" perde mais do que isso. A mudança de regra impôs a "dívida" um retorno esperado negativo. Trabalhando num espaço $\mathrm{R}^{2}$ podemos demonstrar isto graficamente:

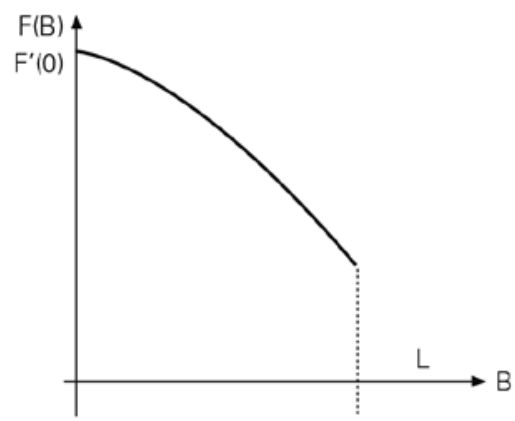

A utilidade esperada da renda varia em função da "dívida pública interna". Existe um máximo de riqueza dos agentes destinada à liquidez apresentado na equação (1). O resultado da quebra que impõe um retorno negativo torna a utilidade esperada da renda decrescente — o sinal da primeira derivada em (7).

Nestas condições, o nível ótimo é zero de "dívida pública interna" e tudo em moeda. Devido a isso, a utilidade esperada do rendimento dos agentes privados frente a ativos de liquidez é função apenas do imposto inflacionário. A perda é menor do que com dívida.

$$
F(0)=E V\{-L \pi\}
$$

B) quando a quebra de regra não é muito forte $(\alpha<1 / \pi)$ : a quebra de regra corrigiu uma parcela da inflação vigente no rendimento da "dívida pública interna". ${ }^{46}$ Se isto ocorre, $\mathrm{E}\{\mathrm{i}(1+\alpha \pi)\}>0$.

\footnotetext{
${ }^{46} \mathrm{Na}$ verdade este caso é diferente ao último apenas na diversificação de ativos. No último caso, a
} 
Pela equação (7), a primeira derivada é positiva. Este é um caso em que a solução ótima será não reter nada em termos de moeda como ativo de liquidez. No mínimo a "dívida pública interna" perde um pedaço da inflação vigente enquanto que a moeda perde a inflação vigente. A mudança de regra impôs uma perda aos detentores da "dívida" embora ele seja menor que a perda da inflação. Trabalhando num espaço $\mathrm{R}^{2}$ podemos demonstrar isto graficamente:

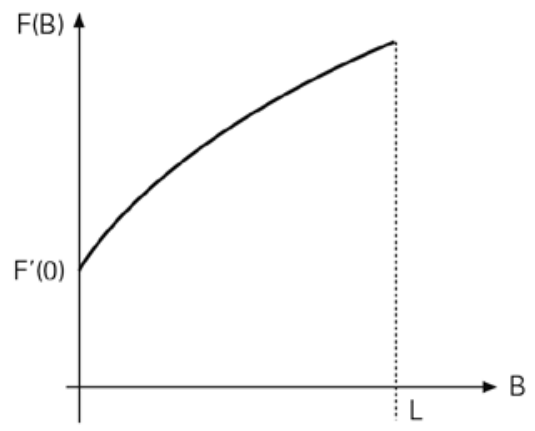

A utilidade esperada da renda varia em função da "dívida pública interna". Existe um máximo de riqueza dos agentes destinada à liquidez apresentada na equação (1). O resultado da quebra de regra não foi suficiente para tornar o sinal da equação (7) negativo. A quebra foi pequena e comparada à moeda, a perda é menor. O nível ótimo nestas condições é zero de moeda e tudo em "dívida pública interna". Devido a isso, a utilidade esperada do rendimento dos agentes privados frente a ativos de liquidez é função apenas do rendimento da "dívida pública interna" como se pode ver na equação (10) a seguir:

$$
F(B)=E V\{[i(1+\alpha \pi)] B\}
$$

quando a quebra de regra não é muito forte $(\alpha<1 / \pi)$ : a quebra de regra corrigiu uma parcela da inflação vigente no rendimento da "dívida pública interna".

Se isto ocorre, $\mathrm{E}\{\mathrm{i}(1+\alpha \pi)\}>0$.

Para este caso, existem dois sinais da primeira derivada na equação (7): primeiro ela é positiva depois ela é negativa. Este é um caso onde a solução ótima será uma diversificação entre moeda e "dívida pública interna". Como antes, no mínimo a "dívida pública interna" perde um pedaço da inflação vigente enquanto que a moeda perde a inflação vigente. A mudança de regra impôs uma perda aos detentores da "dívida" embora ele seja menor que a perda da inflação. Trabalhando num espaço $\mathrm{R}^{2}$ podemos demonstrar isto graficamente:

utilidade da renda cresce e depois diminui. 


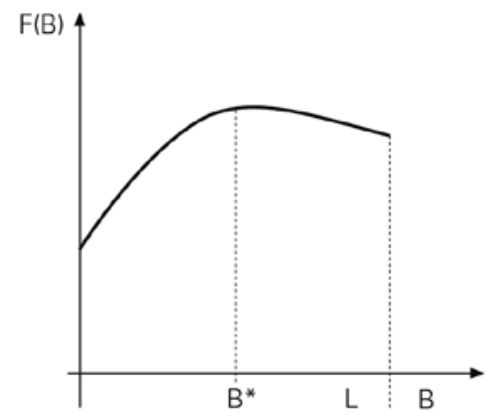

A utilidade esperada da renda varia em função da "dívida pública interna". Existe um máximo de riqueza dos agentes destinada à liquidez visto na equação (1) e um nível ótimo de diversificação entre moeda e "dívida pública interna", $B$ ", visto que a primeira derivada - equação (7) — primeiro cresce e depois decresce.

\section{CONCLUSÕES}

1. A experiência histórica institucional evidenciou um conjunto bem articulado de regras que possibilitou entendimento sobre o papel e atuação dos participantes no mercado de dívida pública interna: setor público, instituições financeiras e agentes privados.

2. Esta articulação foi formada pela regra de aplicação da correção monetária, regras criadas para o Sistema Financeiro pela Autoridade Monetária e as regras criadas pelo Sistema Financeiro para os agentes privados.

3. Falando especificamente do efeito desta articulação sobre a dívida pública interna, podemos dizer que a mesma assumiu a função de reserva de valor da moeda.

4. Aceita a configuração institucional da dívida pública, a alocação ótima entre moeda e a dívida na parte da riqueza financeira dos agentes depende do tamanho da quebra de regra e da resposta da utilidade esperada dos agentes frente aos acréscimos de dívida interna nesta forma de riqueza. ${ }^{47}$

a. se a quebra de regra for superior ao mecanismo de indexação montado para corrigir nominalmente o débito, toda a riqueza será alocada em moeda;

b. se a quebra de regra for inferior ao mecanismo de indexação montado paracorrigir nominalmente o débitos, a alocação, apesar da inflação, será composta por:

b.1. apenas dívida pública interna se qualquer acréscimo de dívida pública nariqueza financeira dos agentes levar a uma utilidade esperada do rendimento crescente;

\footnotetext{
${ }^{47}$ As situações analisadas pressupõem agentes com comportamento avesso ao risco.
} 
b.2. dívida pública e moeda se o acréscimo de dívida pública na riqueza finan-ceira dos agentes levar a uma utilidade esperada do rendimento decrescente (este é o caso de mais comum).

5. Face ao descrito, mesmo com rentabilidade real negativa na série que adotamos como proxy, a alocação de dívida pública na riqueza financeira dos agentes privados sempre foi crescente porque a mesma servia como um hedge da moeda na sua função de reserva de valor.

\section{APÊNDICE}

Quadro 1: A evolução da Dívida Interna Pública na riqueza financeira dos agentes (TITULOS) e a evolução do seu retorno real (SELIC)

\begin{tabular}{|c|c|c|}
\hline ANOS & TITULOS & SELIC ${ }^{48}$ \\
\hline 1974 & 17.62849 & -12.84008 \\
\hline 1975 & 20.55041 & -5.792556 \\
\hline 1976 & 24.16976 & -3.494521 \\
\hline 1977 & 25.23095 & 2.274783 \\
\hline 1978 & 25.08454 & 3.971918 \\
\hline 1979 & 23.44311 & -19.56545 \\
\hline 1980 & 19.61795 & -30.38861 \\
\hline 1981 & 24.73177 & -3.034330 \\
\hline 1982 & 28.08451 & 9.828659 \\
\hline 1983 & 26.22221 & -5.734314 \\
\hline 1984 & 26.44927 & -1.645473 \\
\hline 1985 & 35.68459 & -2.757425 \\
\hline 1986 & 32.02469 & -7.295173 \\
\hline 1987 & 35.79242 & -12.17380 \\
\hline 1988 & 44.83717 & 1.769414 \\
\hline 1989 & 53.08030 & 33.16116 \\
\hline 1990 & 40.35019 & -20.51684 \\
\hline 1991 & 29.48641 & 9.757530 \\
\hline 1992 & 42.31167 & 31.12755 \\
\hline 1993 & 45.71782 & 12.52903 \\
\hline
\end{tabular}

continua na página seguinte

\footnotetext{
${ }^{48}$ Não consideramos taxas líquidas porque a tributação foi alterada durante todo o período de análise por diversas vezes. Se o nosso foco não fosse a mudança de regra da dívida, também poderíamos considerar no modelo taxas líquidas com um componente estocástico na tributação.
} 


\begin{tabular}{lll}
\hline 1994 & 49.05151 & 5.006783 \\
1995 & 41.46909 & 33.37513 \\
1996 & 57.46395 & 16.53172 \\
1997 & 60.53340 & 16.09649 \\
1998 & 72.35685 & 26.62986 \\
1999 & 79.68365 & 4.674267 \\
2000 & 73.92403 & 6.270552 \\
\hline
\end{tabular}

Fonte: IPEADATA e Boletim do Banco Central (vários anos) ${ }^{49}$

Gráfico 1

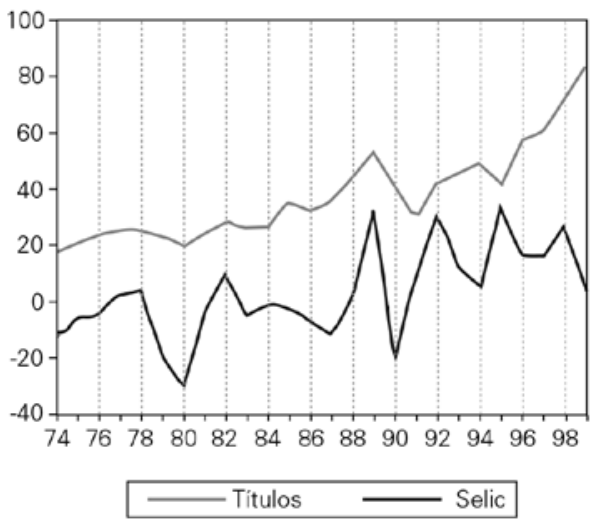

Gråfico 2

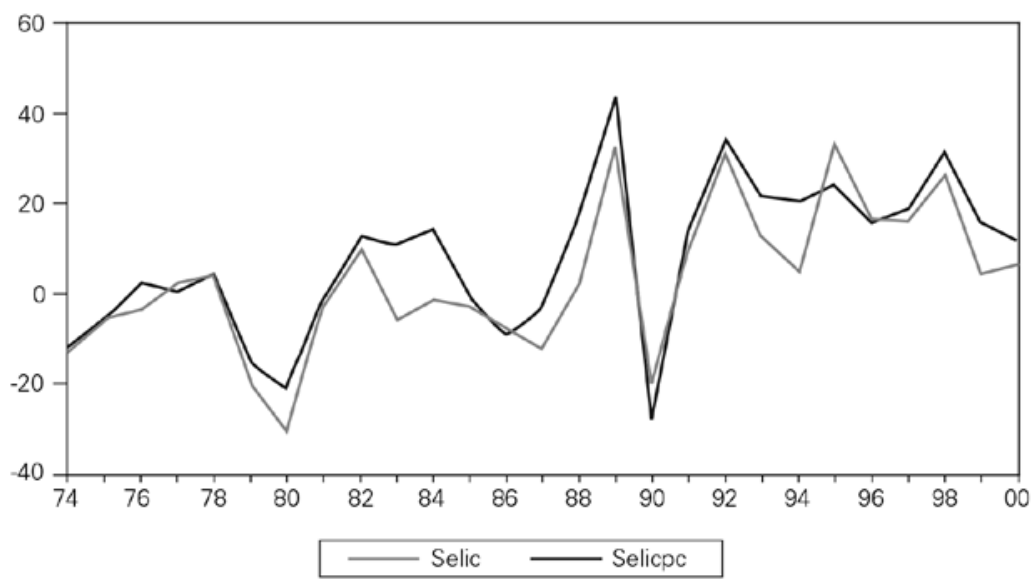

${ }^{49}$ A série TITULOS representa a dívida pública fora do Banco Central sobre o M4. Algumas imputações foram feitas nos anos setenta dada a dificuldade de se preservar o conceito de dívida fora do Banco Central. A série SELIC foi deflacionada pelo IGP-DI. Alteramos o deflator para o IPC e não tivemos mudança significativa da série real. A correlação entre ambas foi de 91,9547\%. Veja gráfico 2 deste apêndice. 


\section{REFERÊNCIAS BIBLIOGRÁFICAS}

ANDIMA. Associação Nacional das Instituições de Mercado Aberto. Séries históricas — dívida pública, 1993.

ARVATE, P. R. Quando a regra é quebrar a regra: uma versão institucional sobre a experiência brasileira de endividamento público interno. Dissertação de doutorado apresentada a FEA/USP, 1999.

ARVATE, P. R. \& LEITE, M. G. "Participação relativa da dívida pública interna na riqueza financeira dos agentes privados: um estudo exploratório”. Texto para discussão interna da EAESP/FGV-SP, n. 96, 2000.

BARROS, J. M. \& ALMEIDA JÚNIOR, M.F. Análise do ajuste do Sistema Financeiro. Ministério da Fazenda, maio de 1997.

BLANCHARD, O. \& FISCHER, S. Lectures on Macroeconomics. MIT Press, 1989.

BRANDÃO, C. em CYSNE, R. P. (org,). Política monetária: uma transição do modelo atual para o modelo clássico. Publicação interna da EPGE/FGV-RJ, número 262, 1995.

CYSNE, R. P. \& SIMONSEN, M. H. Macroeconomia. Editora ao Livro Técnico, 1989.

COSTA E SILVA, E.C.de. Os Fundos de Pensão na Sociedade do Conhecimento. Dissertação de Mestrado apresentada na FGV/EAESP em 1996.

FISCHER. S. "Demand for indexed bonds". Journal of Political Economy, 1985.

LLUSSÁ, F. A. J. Credibilidade e Administração da Dívida pública: um estudo para o Brasil. Dissertação de mestrado apresentada a EAESP/FGV-SP.

NORTH, D. Institutions, Institutional change amd Economic Performance. Cambridge University Press, 1990

NERI, M. \& CAMARGO, J.M. "Efeitos distributivos das reformas estruturais no Brasil" em BAUMANN, Renato (org). Brasil, uma década em transição. Editora Campus /CEPAL, 2000.

PINOTTI, M. C. \& PASTORE, A. C. "Inflação e estabilização: algumas lições da experiência brasileira”. Revista Brasileira de Economia, 53 (1): 3-40. Janeiro/Março de 1999.

PUGA, F. P. "Sistema Financeiro Brasileiro: reestruturação recente, comparações internacionais e vulnerabilidade à crise cambial”. Texto para discussão interna do BNDES, n. 68, março de 1999.

RESENDE, A. L. “A Política Brasileira de Estabilização: 1963/1968”. Pesquisa e Planejamento Econômico, 12 (3), Dezembro, 1982. 